\title{
Laboratory Investigation and Molecular Epidemiology of H1N1pdm Virus
} 2012-2013 from India

\author{
Shashi Sharma*, Gaurav Joshi, Paban Dash K and Parida MM
}

Division of Virology, Defence R\&D Establishment (DRDE), Jhansi Road, Gwalior-474002, MP, India

\begin{abstract}
Influenza A virus is the most unpredictable global threat, past pandemic witnessed the community swaps happened due to this virus. The recent emergence of H7N9 in China is the result of new and recent reassortmant of Influenza A virus. Emergence of a novel human influenza A virus (H1N1pdm) in 2009 is an unprecedent event of molecular virology. This novel emerged virus affected millions of persons and raised WHO pandemic alert to phase 6 . Therefore continuous monitoring is required to have adequate genome information and to track mutations during course of viral evolution. In present study we investigated acute phase suspected H1N1pdm clinical samples from North India 2012-2013. H1N1pdm virus confirmed positive samples were proceeded for virus isolation in MDCK cells. Complete $\mathrm{HA}$ gene was deciphered and phylogenetic analysis of Indian H1N1pdm virus isolate was carried out with respect to globally diversified $\mathrm{H} 1 \mathrm{~N} 1 \mathrm{pdm}$ virus. CDC Real time RT-PCR revealed $15 \%$ positivity for $\mathrm{H} 1 \mathrm{~N} 1 \mathrm{pdm}$ virus. Complete HA gene sequence characterization of Indian H1N1pdm 2012-2013 virus and their phylogenetic analysis with respect to circulating global viruses revealed continuous circulation of cosmopolitan Clade VII in India.
\end{abstract}

In the course of its evolution, 2009-2013 the virus acquired many mutations and which could be responsible for severity of this virus and emergence of new virus subtypes. India also witnessed high morbidity and mortality reported from all parts of the country. This study clearly indicates that recently reported cosmopolitan clade VII has undergone positive selection in India as well globally revealed continuous circulation of clade VII since 2009. This study of recent H1N1pdm Indian virus isolate will facilitate future epidemiological surveillance in Indian subcontinent and abroad.

Keywords: Molecular epidemiology; H1N1pdm; Swine flu.

\section{Introduction}

The 2009 Swine Flu pandemic is caused by a novel reasserted H1N1 subtype of H1N1 influenza A virus that had not been recognized previously in swine or humans. This newly emerged strain represents a quadruple reassortment of two swine strains, one human strain, and one avian strain of influenza. The largest proportion of genes comes from swine influenza viruses $(30.6 \%$ from North American swine influenza strains, $17.5 \%$ from Eurasian swine influenza strains), followed by North American avian influenza strains (34.4\%) and human influenza strains (17.5\%). Influenza A virus is a member of family Orthomyxoviridae. Based on the antigenicity, virus may be classified into 17 Hemagglutinin (H1-H16) and 10 Neuraminidase (N1-N9) subtypes [1]. Influenza A virus genome is composed of eight segments of single-stranded, negative-sense RNA and each of which encodes ten proteins. The HA protein is critical for binding to cellular receptors and fusion of the viral and endosomal membranes [2]. Several reports described both emergence and pandemic potential of the virus in the perspective of earlier pandemic influenza viruses of 1918 (H1N1), 1957 $(\mathrm{H} 2 \mathrm{~N} 2)$ and $1968(\mathrm{H} 3 \mathrm{~N} 2)$ through comparison of the available genetic sequence data [3]. Since April 2009, the novel swine-origin influenza A (H1N1pdm) virus has rapidly spread across the globe. World Health Organization declared the outbreak a global pandemic in June 2009 [4].

The H1N1 virus has caused a considerable number of deaths within a short duration since its emergence. Several reports about the comparison of HA gene sequence with those of the earlier influenza pandemics have shown that human-specific markers supporting efficient transmissibility of these viruses in human are present in the H1N1pdm virus $[1,5]$. Clinical investigation and molecular epidemiology study is therefore required for continuous monitoring of this virus.

In India, the H1N1pdm virus is circulating through its emergence continuously and viral cases are being reported from different parts of the country in post pandemic phase [6-9]. Increased number of fatal cases was also reported from different states, that clearly indicates that 2009 (H1N1) virus is adapted to the environment and now has become endemic in the country. Many of Indian states succumbed to the swine flu epidemic. The state Gujarat was at the top in H1N1pdm mortalities in year 2013 (till March 24) with 150 out of the 818 cases proving to be fatal whereas in Delhi 16 deaths out of 1,461 cases reported same period.

Further, continuous monitoring of the evolution of this virus is advocated to track the mutations that may increase pathogenicity and/ or transmissibility. Understanding the virus evolution within India in relation to global diversification of the virus is also essential. So far, limited genome sequence data is available for Indian H1N1pdm virus. The circumstances surrounding the emergence of this pathogen, and the factors that facilitated the initial cross-species transmission, are still not fully understood. It became apparent in the early days of the outbreak that the virus can be directly transmitted between humans. Therefore present study was carried out to reveal molecular epidemiology of H1N1pdm virus from India in year 2012-2013. This study aimed to add the sequence information recently circulating H1N1pdm virus from India. The phylogenetic analysis of H1N1pdm virus from 2009-2013 of Indian isolates revealed continuous circulation of clade VII in India.

\section{Materials and Methods}

\section{Clinical samples and case definition}

A total of 100 acute phase respiratory swabs (Nasopharyngeal/

*Corresponding author: Dr. Shashi Sharma, Division of virology, Defence R\&D Establishment, Jhansi Road, Gwalior-474002, M.P, India, Tel: +91-751-2234514; Fax: +91-751-2341148; E-mail: shashisharma@drde.drdo.in

Received November 06, 2014; Accepted December 25, 2014; Published January 04,2015

Citation: Shashi S, Gaurav J, Paban Dash K, Parida MM (2015) Laboratory Investigation and Molecular Epidemiology of H1N1pdm Virus 2012-2013 from India. J Phylogen Evolution Biol 3: 139. doi:10.4172/2329-9002.1000139

Copyright: $\odot 2015$ Shashi S, et al. This is an open-access article distributed under the terms of the Creative Commons Attribution License, which permits unrestricted use, distribution, and reproduction in any medium, provided the original author and source are credited. 
Throat/Nasal) samples suspected for H1N1pdm virus, from the patients having history of suspected Influenza A like illness were referred from sentinel hospitals in Gwalior, India (G.R. Medical College, BIMR Hospital) for the laboratory investigation of H1N1pdm outbreak during 2012-2013. The detailed clinical history and epidemiological information were provided along with samples. The case definitions recommended by WHO guidelines were used for probable and confirmed cases.

\section{Laboratory screening of $\mathrm{H} 1 \mathrm{~N} 1 \mathrm{pdm}$ suspected clinical samples}

Viral RNA was extracted from $140 \mu \mathrm{l}$ of clinical sample and cell culture supernatant (Isolates) by using QIAamp viral RNA mini kit (Qiagen, Germany) in accordance with the manufacturer's instructions. Finally, RNA was eluted in $50 \mu \mathrm{l}$ of elution buffer and stored at $-80^{\circ} \mathrm{C}$ until use.

The CDC Real-time RT-PCR assay was used for novel swine flu virus identification in Mx 3005P quantitative PCR system (Stratagene, USA). The assay is based on Taqman chemistry including a panel of oligonucleotide primers and dual labeled hydrolysis probe sets [universal Influenza A (Inf A), swine influenza A (swInf A), swine H1 (swH1), and RNaseP (RP)] employing Invitrogen SuperScript ${ }^{\mathrm{TM}} \mathrm{III}$ Platinum ${ }^{\circ}$ one step quantitative kit (Invitrogen, USA). The amplification was carried out in a $25 \mu \mathrm{l}$ reaction volume according to the CDC instruction and standard thermal profile for sample screening [10]. The protocol followed as such used by us previously [11].

\section{Virus isolation and genetic characterization}

All the clinical samples were processed in Biosafety Level -3 Laboratory. Madin Darby Canine Kidney (MDCK) cells purchased from NCCS, Pune were maintained in Modified Eagle's Medium (MEM) (Sigma-Aldrich, St. Louis, MO) supplemented with 5\% fetal bovine serum (FBS) (Sigma-Aldrich) at $37^{\circ} \mathrm{C}$ in a humidified $5 \% \mathrm{CO}_{2}$ atmosphere. The clinical materials (throat and nasal swabs) obtained from patients were inoculated in MDCK cell lines at $90 \%$ confluency for virus isolation as per standard protocol [12]. Tissue culture fluid was harvested after observing MDCK cell lines for cytopathic effect. Morphological changes of MDCK cells were photographed with an inverted microscope (Olympus IX 71) at 0 to $72 \mathrm{hr}$. The presence of pandemic $\mathrm{H} 1 \mathrm{~N} 1$ virus in infected culture fluid was demonstrated by HA test [13], RT-PCR and CDC real time RT-PCR (CDC, 2009) [4].

One step RT-PCR was carried out to amplify full HA gene segments using the recommended WHO-CDC whole HA gene amplification primers (CDC, 2009) [4]. HA gene segment was amplified in six fragments with $100 \mathrm{bp}$ overlapping sequence in order to get at least four fold sequence coverage. To amplify each segment, $5 \mu$ of RNA was added to a $25 \mu$ l of master mix containing $2.5 \mu \mathrm{l}$ 10X PCR buffer, $1.5 \mu \mathrm{l}$ $\mathrm{MgCl}_{2}(3 \mathrm{mM}), 0.5 \mu \mathrm{ldNTP}(200 \mu \mathrm{M}$ each), 0.5 Reverse Transcriptase (0.4 units/ $\mu \mathrm{l}), 0.5 \mu \mathrm{l}$ RNase inhibitor (0.4 units/ $\mu \mathrm{l}), 0.5 \mu \mathrm{l}$ Taq DNA polymerase $(0.05$ units $/ \mu \mathrm{l}), 0.25 \mu \mathrm{l}$ of respective forward and reverse primers and $13 \mu \mathrm{l}$ of molecular biology grade water. The One-step RTPCR was carried out using Enhanced Avian HS RT-PCR kit (Sigma, USA). The PCR amplification was carried out in a final volume of 25 $\mu \mathrm{l}$ in a thermal cycler (Bio-Rad, USA). The thermal profile followed as standardized previously (Sharma et al., 2013) [11]. The PCR products were gel purified from $1 \%$ agarose gel using the QIAquick gel extraction kit (Qiagen, Germany) and used as template in sequencing reactions.

\section{Sequencing characterization}

Double pass sequencing was carried out employing big dye terminator cycle sequencing ready reaction kit (Perkin-Elmer, Applied
Biosystems, USA) on an ABI 3130 sequencer [11]. The reaction mixture was column purified and the DNA was dried in vacuum. The DNA pellet was resuspended in $15 \mu \mathrm{l}$ of hidiformamide, heated at $95^{\circ} \mathrm{C}$ for 5 min before loaded on the ABI 310 automated DNA sequencer (Applied Biosystems, USA).

The nucleotide sequences were retrieved, edited and analysed using the SeqScape (Applied Biosystems, USA) and EditSeq and MegAlign modules of Lasergene 5 software package (DNASTAR Inc, USA). Multiple sequence alignment was carried out employing MUSCLE [14]. The deduced amino acid was determined from the nucleotide sequence using the EditSeq module of Lasergene 5 software package (DNASTAR Inc, USA). The percent nucleotide identity and percent amino acid identity values were calculated as pairwise p-distances. Extensive phylogenetic analysis based on full HA gene (1701nt) were carried out by including 45 globally diverse H1N1pdm sequences (Table 2) respectively using MrBayes version 3.1.2 [15]. The Bayesian tree was inferred by running a Markov-chain Monte Carlo algorithm for 1, million generations, sampling at every $100^{\text {th }}$ generation with a burn in setting of $10 \%$ of generations. The GTR+G+I model (general timereversible model with gamma-distributed rates of variation among sites and a proportion of invariable sites) was found to be the best-fit model for our dataset. Convergence was assessed using mean SD in partition frequency values by using a threshold of 0.01 .

\section{Results}

\section{Case definition and laboratory diagnosis of H1N1pdm samples}

A total 100 clinical samples (WHO category C cases) during post pandemic phase with Influenza like illness from Gwalior region from 2012-2013 were investigated for H1N1pdm virus. ILI suspected samples were received from patients presented to sentinel hospitals for healthcare. These samples with detailed case history were sent to DRDE, Gwalior for laboratory diagnosis. All the samples presented with clinical profile of fever (axilla, Oral $>38.0^{\circ} \mathrm{C}$ ), cough, sore throat, nasal catarrh and shortness of breath. Nine samples were found positive for H1N1pdm virus by WHO approved CDC Real Time RT-PCR (Table 1).

\section{Isolation and identification of H1N1pdm virus}

Positive samples were attempted for the H1N1pdm virus isolation in MDCK cells through three blind passages resulted in one successful Indian H1N1pdm isolation. Initially, H1N1pdm virus infection in MDCK cells was analysed microscopically for the appearance of prominent cyotopathic effects (granulation, clustering and finally total detachment from the adherent surface) till 48-72hpi (Figure 1A). Infected cell culture supernatant was harvested at this stage and used for further sequence characterization. Hemagglutination (HA) titre with guinea pig RBC was determined in infected culture supernatant was found 16HA units for successful isolation of 2012-2013 H1N1pdm virus (Figure 1B). Virus isolation was also confirmed at genomic level with WHO approved CDC RT-PCR and Real time RT-PCR primer set specific for H1N1pdm virus (Figures $1 \mathrm{C}$ and 1D).

\section{RT-PCR for the amplification of complete HA gene}

In 2012-2013, one representative of each year H1N1pdm virus (A/ India/Gwl_06/2012 and A/India/Gwl_13/2013) with travel history and severe complications (Though finally recovered from infection) from Gwalior was selected for complete HA gene amplification. This sample at passage level three in MDCK cells were used for the purpose and were subjected to complete HA gene amplification. The editing and alignment of sequences of overlapping fragments led to sequence 
Citation: Shashi S, Gaurav J, Paban Dash K, Parida MM (2015) Laboratory Investigation and Molecular Epidemiology of H1N1pdm Virus 2012-2013 from India. J Phylogen Evolution Biol 3: 139. doi:10.4172/2329-9002.1000139

Page 3 of 7

\begin{tabular}{|c|c|c|c|c|c|l|}
\hline SI.No & Details of clinical samples & Sampling Date & Age (Yr/month) & Gender & Ct value (swH1) & Clinical Symptoms \\
\hline 1 & DRDE 02_12 & $28 / 05 / 12$ & $54 \mathrm{yr}$ & $\mathrm{M}$ & 34 & Fever, oral, cough, difficulty in breathing \\
\hline 2. & DRDE 06_12 & $31 / 08 / 12$ & $36 \mathrm{yr}$ & $\mathrm{M}$ & 38 & Fever, oral, cough, Sore throat, difficulty in breathing \\
\hline 3. & DRDE 18_12 & $14 / 09 / 12$ & $48 \mathrm{yr}$ & $\mathrm{F}$ & 39 & Fever, cough, shortness of breath \\
\hline 4. & DRDE 23_12 & $03 / 10 / 12$ & $28 \mathrm{yr}$ & $\mathrm{M}$ & 40 & cough, shortness of breath \\
\hline 5. & DRDE 24_12 & $03 / 10 / 12$ & $35 \mathrm{yr}$ & $\mathrm{M}$ & 39 & Fever, oral, cough, sore throat, shortness of breath \\
\hline 6. & DRDE 27_12 & $10 / 10 / 12$ & $55 \mathrm{yr}$ & $\mathrm{F}$ & 37 & Fever, oral, cough, sore throat, nasal catarrh, shortness of breath \\
\hline 7. & DRDE-28_12 & $10 / 10 / 12$ & $40 \mathrm{yr}$ & $\mathrm{F}$ & 30 & Fever, oral, cough, sore throat, nasal catarrh, shortness of breath \\
\hline 8. & DRDE-33_12 & $31 / 10 / 12$ & $18 \mathrm{yr}$ & $\mathrm{M}$ & 38 & cough, sore throat, shortness of breath \\
\hline 9. & DRDE-03_13 & $16 / 02 / 2013$ & $39 \mathrm{yr}$ & $\mathrm{M}$ & 37 & Fever, oral, cough, sore throat, nasal catarrh, shortness of breath \\
\hline 10. & DRDE-13_13 & $30 / 07 / 2013$ & $30 \mathrm{yr}$ & $\mathrm{M}$ & 35 & Fever, cough, sore throat, nasal catarrh, shortness of breath \\
\hline 11. & DRDE-16_13 & $10 / 08 / 2013$ & $45 \mathrm{yr}$ & $\mathrm{F}$ & 38 & Fever, cough, sore throat, nasal catarrh, shortness of breath \\
\hline 12. & DRDE-25_13 & $20 / 09 / 2013$ & $18 \mathrm{yr}$ & $\mathrm{M}$ & 37 & Fever, cough, sore throat, shortness of breath \\
\hline
\end{tabular}

Table 1: Details of positive cases for H1N1pdm virus during investigation of suspected samples from 2012- 2013.

Fig la

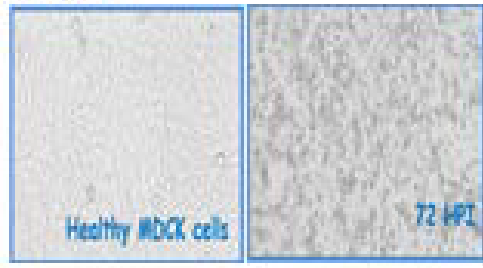

Fig $1 b$

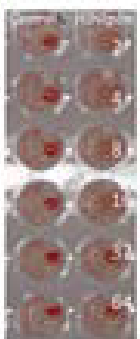

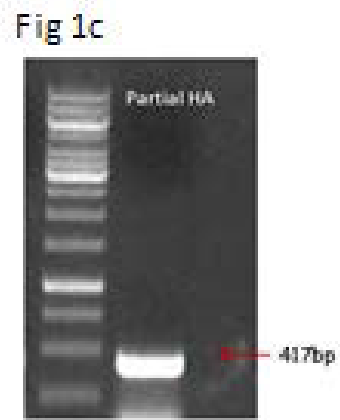

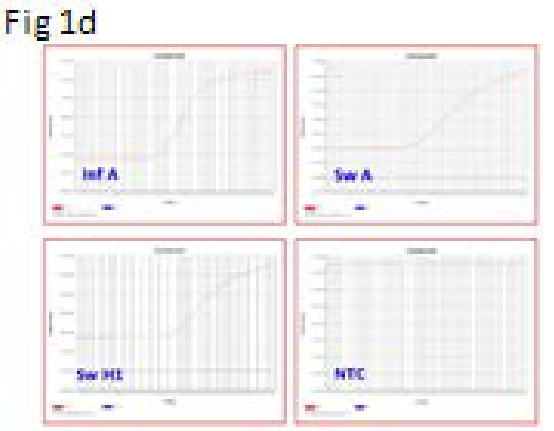

Figure 1: Charaacterization of $2012 \mathrm{H1N1pdm}$ virus isolate.Figure 1: CPE; Figure 1b: HA; Figure 1c: RT-PCR; Fig 1d: Real time RT-PCR

(A) Microscopic Photograph of Healthy and Influenza A (H1N1pdm) virus isolate infected Madin Darby Canine Kideny Cells. A. Mock MDCK cells, B.H1N1pdm virus infected MDCK cells. (B) H1N1pdm virus characterization by Hemagglutination assay. (C) RT-PCR amplification of partial HA gene with CDC primer set. (D) CDC Real time RT-PCR.

information of complete HA gene. Complete HA gene of isolate deciphered $1701 \mathrm{nt}$. The complete HA gene sequence of virus isolate was deposited in GenBank under accession number KC894815.

\section{Analysis of the HA gene of the Indian H1N1pdm virus}

The genome sequences of representative Influenza A (H1N1pdm) viruses of diverse geographical origins were retrieved from NCBI GenBank database from the period of 2009-2012 (Table 2). Comparative HA gene sequence analysis with A/California/04/2009 H1N1pdm prototype strain of the Indian isolates revealed $>98 \%$ (ranged between 98.9-99.8\%) nucleotide identity. The PAD within HA genes of 2012 Indian isolate sequenced in this study was found $98.9 \%$ in compared to prototype (California/04/2009/H1N1) virus (Figure 2). The virus sequenced in this study revealed $>99 \%$ amino acid sequence identity for the HA protein of previous Indian H1N1pdm virus isolated in 2009-2011 (Pune/NIV6447/2009, Pune/NIV8489/2009, Blore/NIV236/2009, Blore/NIV310/2009, Mum/NIV5442/2009, Gwl/ dsc/2010, Gwl/01/2011, Gwl/02/2011).

\section{Analysis of HA gene segment}

Comparison of HA gene segment at protein level with respect to A/California/04/2009 (H1N1pdm prototype strain) and previously sequenced Indian strain revealed a total of 11 substitutions scattered throughout the gene segment in Indian viruses sequenced in this study. The sequence alignment revealed amino acid replacement throughout the aligned region. The amino acid substitutions among H1N1pdm virus (sequenced in this study) vis-a-vis prototype California/04/2009 and other Indian isolates are shown in Table 3. The clade specific mutations in HA gene, HA: P100S, S220T, I338V were reported amongst all the Indian isolates. P100S substitution observed in all Indian isolates 
Citation: Shashi S, Gaurav J, Paban Dash K, Parida MM (2015) Laboratory Investigation and Molecular Epidemiology of H1N1pdm Virus 2012-2013 from India. J Phylogen Evolution Biol 3: 139. doi:10.4172/2329-9002.1000139

Page 4 of 7

\begin{tabular}{|c|c|c|c|c|}
\hline SI.No & Strain & Year & Geographic origin & clade \\
\hline 1 & California/04 & 2009 & USA & 1 \\
\hline 2 & California/07 & 2009 & USA & 1 \\
\hline 3 & Hamburg/4 & 2009 & Europe & II \\
\hline 4 & Kansas/03 & 2009 & US & II \\
\hline 5 & England/195 & 2009 & UK & III \\
\hline 6 & New York/3177 & 2009 & USA & III \\
\hline 7 & Osaka/1 & 2009 & Japan & IV \\
\hline 8 & Korea/01 & 2009 & Korea & IV \\
\hline 9 & Beijing/3 & 2009 & China & V \\
\hline 10 & Hyd-NIV51 & 2009 & India & V \\
\hline 11 & Wisconsin/629D00008 & 2009 & USA & V \\
\hline 12 & India-Pune/NIV6196 & 2009 & India & VI \\
\hline 13 & India-NIV10604 & 2009 & India & $\mathrm{VI}$ \\
\hline 14 & NewYork/3324 & 2009 & USA & $\mathrm{VI}$ \\
\hline 15 & Shanghai/143T & 2009 & China & $\mathrm{VI}$ \\
\hline 16 & Shanghai/1 & 2009 & China & VII \\
\hline 17 & Ohio/07 & 2009 & USA & VII \\
\hline 18 & Denmark/523 & 2009 & Europe & VII \\
\hline 19 & pune/NIV8489 & 2009 & India & VII \\
\hline 20 & pune/NIV6447 & 2009 & India & VII \\
\hline 21 & Mum/NIV5442 & 2009 & India & VII \\
\hline 22 & Blore/NIV236 & 2009 & India & VII \\
\hline 23 & Mum/NIV9945 & 2009 & India & VII \\
\hline 24 & pune/NIV10278 & 2009 & India & VII \\
\hline 25 & pune/NIV9355 & 2009 & India & VII \\
\hline 26 & Delhi/NIV3704 & 2009 & India & VII \\
\hline 27 & Omsk/02 & 2009 & Russia & VII \\
\hline 28 & Netherland/2631 & 2010 & Europe & VII \\
\hline 29 & Assam/2220 & 2009 & India & VII \\
\hline 30 & Shanghai/3162T & 2011 & China & VII \\
\hline 31 & St.Petersburg/CRIE-GOVM & 2011 & Russia & VII \\
\hline 32 & Rio Grande do sul/361 & 2011 & Brazil & VII \\
\hline 33 & Nizhnii Novgorod/CRIE-BLM & 2011 & Russia & VII \\
\hline 34 & Georgia & 2012 & Eurasia & VII \\
\hline 35 & Bangalore-NIM & 2010 & India & VII \\
\hline 36 & GWL-DSC & 2010 & India & VII \\
\hline 37 & GWL-01 & 2011 & India & VII \\
\hline 38 & GWL-02 & 2011 & India & VII \\
\hline 39 & Gwl-06 & 2012 & India & VII \\
\hline 40 & Gwl-13 & 2013 & India & VII \\
\hline
\end{tabular}

was located in the antigenic site $\mathrm{E}$ and S202T substitution observed in Indian isolate sequenced in this study (A/India/GWL_06/2012) was located in antigenic site B. Further, substitution S220T (in all four previously sequenced Indian viruses) was found in the vicinity of site D. The residue position for the HA is the numbering considered inclusive of the signal peptide.

\section{Rapid and Real time detection of Oseltamivir resistance}

All positive clinical samples were screened by RT-PCR/RFLP assay.

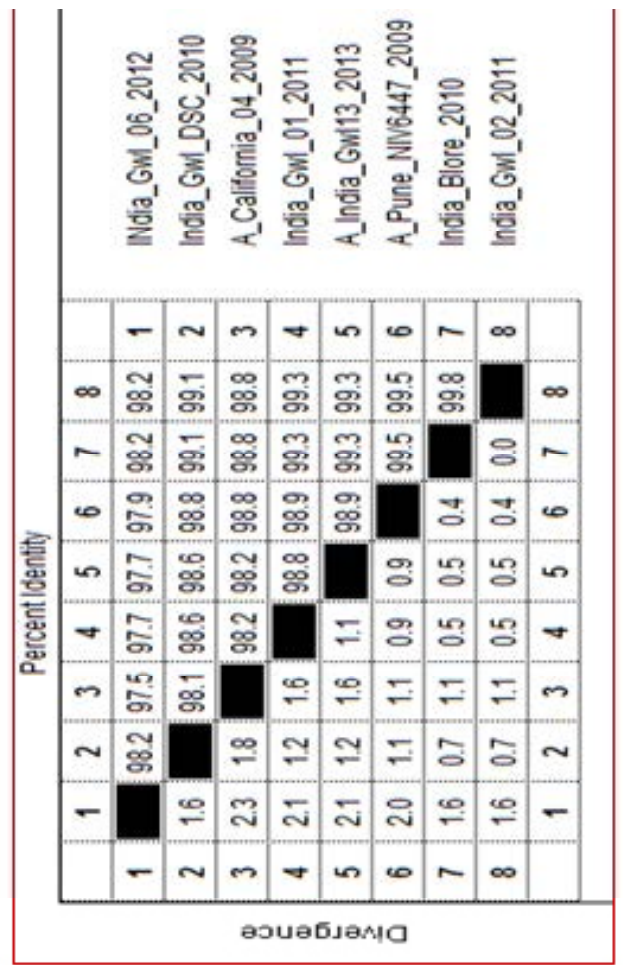

Figure 2: Multiple sequence alighment of deduced amino avid sequence of $\mathrm{HA}$ gebe segment indian H1N1pdm viruses 2009-2013.

Amino acid sequence divergence of $2012 \mathrm{H} 1 \mathrm{~N} 1 \mathrm{pdm}$ virus isolate sequenced in this study with compare to prototype (California/04/2009) virus and other Indian virus isolates sequenced previously. and investigated in the complete HA gene based phylogenetic analysis in this study.

Note: The isolate in bold font are sequenced in this study.

\begin{tabular}{|c|c|c|c|c|c|c|c|c|c|}
\hline $\begin{array}{c}\text { Gene } \\
\text { segment }\end{array}$ & $\begin{array}{l}\text { Residue } \\
\text { number * }\end{array}$ & A/California/04/2009 & $\begin{array}{c}\text { A/Pune/ } \\
\text { NIV6447/2009 }\end{array}$ & $\begin{array}{c}\text { A/India/Bangalore_ } \\
\text { NIM/2010 }\end{array}$ & $\begin{array}{c}\text { A/India/GWL__ } \\
\text { DSC/2010 }\end{array}$ & $\begin{array}{c}\text { A/India/ } \\
\text { Gwl_01/2011 }\end{array}$ & $\begin{array}{c}\text { A/India/ } \\
\text { Gwl_02/2011 }\end{array}$ & $\begin{array}{c}\text { A/India/ } \\
\text { Gwl_06/2012 }\end{array}$ & $\begin{array}{c}\text { A/Indial } \\
\text { Gwl_13/2013 }\end{array}$ \\
\hline \multirow[t]{11}{*}{ HA } & 4 & $\mathbf{I}$ & $\mathbf{T}$ & I & I & I & I & I & I \\
\hline & 100 & $P$ & $S$ & $S$ & $S$ & $S$ & $S$ & $S$ & $S$ \\
\hline & 202 & $S$ & $S$ & $S$ & $\mathrm{~T}$ & $S$ & $S$ & $\mathrm{~T}$ & $S$ \\
\hline & 214 & $\mathbf{T}$ & A & A & A & A & A & $\mathbf{T}$ & A \\
\hline & 220 & $S$ & $\mathrm{~T}$ & $\mathrm{~T}$ & $\mathrm{~T}$ & $\mathrm{~T}$ & $\mathrm{~T}$ & $\mathrm{~T}$ & $T$ \\
\hline & 245 & $\mathbf{N}$ & $\mathbf{N}$ & $\mathbf{N}$ & $\mathbf{N}$ & I & $\mathbf{N}$ & $\mathbf{N}$ & $\mathbf{N}$ \\
\hline & 246 & $\mathbf{Y}$ & $\mathbf{Y}$ & $\mathbf{Y}$ & $\mathbf{Y}$ & $\mathbf{N}$ & $\mathbf{Y}$ & $\mathbf{Y}$ & $\mathbf{Y}$ \\
\hline & 338 & 1 & V & V & $\mathrm{V}$ & V & V & V & V \\
\hline & 391 & $\underline{E}$ & $\underline{E}$ & $\underline{\mathbf{K}}$ & $\underline{\mathbf{K}}$ & $\underline{\mathbf{K}}$ & $\underline{\mathbf{K}}$ & $\underline{\mathbf{K}}$ & $\underline{\mathbf{K}}$ \\
\hline & 435 & I & I & I & $\mathbf{T}$ & I & I & I & I \\
\hline & 442 & $L$ & $L$ & $L$ & $L$ & $R$ & $L$ & $L$ & $L$ \\
\hline
\end{tabular}

Table 3: Description of major/important non-conservative and clade specific amino acid substitutions among the six Indian $\mathrm{H} 1 \mathrm{~N} 1 \mathrm{pdm}$ virus (sequenced for complete $\mathrm{HA}$ gene 2009-2013) compared to prototype H1N1pdm strain (California/ 04/2009) and other Indian (A/Pune/NIV6447/2009) virus strain (sequenced previously).

Note: Major non conservative changes involving basic to acidic amino acid are written in bold font and also underlined; The hydrophobic to hydrophilic amino acid substitutions and vice-versa are written in bold font. The substitutions involving charged residues to uncharged residues; cyclic to acyclic and vice versa are written in italics. The clade specific substitutions (NP:V100I; NA:V106I; NS1:I123V; HA:S220T, I338V) are written in normal font.

'The residue position for the HA is the numbering considered inclusive of signal peptide. 
Gel electrophoresis of PCR amplicons before and after Bcl I digestion is shown in (Figure 3A). A 224-bp DNA fragment was amplified and viral strains without the $\mathrm{H} 275 \mathrm{Y}$ mutation (H275; wild type) were digested by Bcl I, producing two smaller fragments of 198 and 26bp, which was further confirmed by sequence analysis Figure 3C. Same primers were optimized for SYBR Green Real Time assay, melting curve analysis with the melting curve analysis software of the Mx3005 showed that specific amplicon melts at $81.6^{\circ} \mathrm{C}\left(81.3-81.9^{\circ} \mathrm{C}\right)$. H1N1pdm virus specific amplification and dissociation are shown in (Figure 3B) [16-18].

\section{Phylogenetic analysis}

Extensive phylogenetic analysis based on full HA gene (1701nt; $\mathrm{n}=45$ ) of representative H1N1pdm viruses sampled between 2009. 2012 from different geographical regions along with the Indian isolates revealed seven distinct clades All the Indian isolates sequenced in this study formed a close branch and grouped into clade VII. This clade VII was represented by maximum number of isolates from geographically diverse areas. The tree topology was found similar as discussed earlier [19]. The clade VII, which is the largest clade is represented by H1N1pdm virus isolated from Japan, Mexico, China, Asia and several states of the USA. H3N2 virus was taken as an outgroup for rooting the tree during phylogenetic analysis. All the representative circulating H1N1pdm viruses from India were included in the phylogenetic analysis from 2009-2012.

\section{Discussion}

Influenza cases reported in northern India year around and contribute significantly number of ILI patients seeking health care.

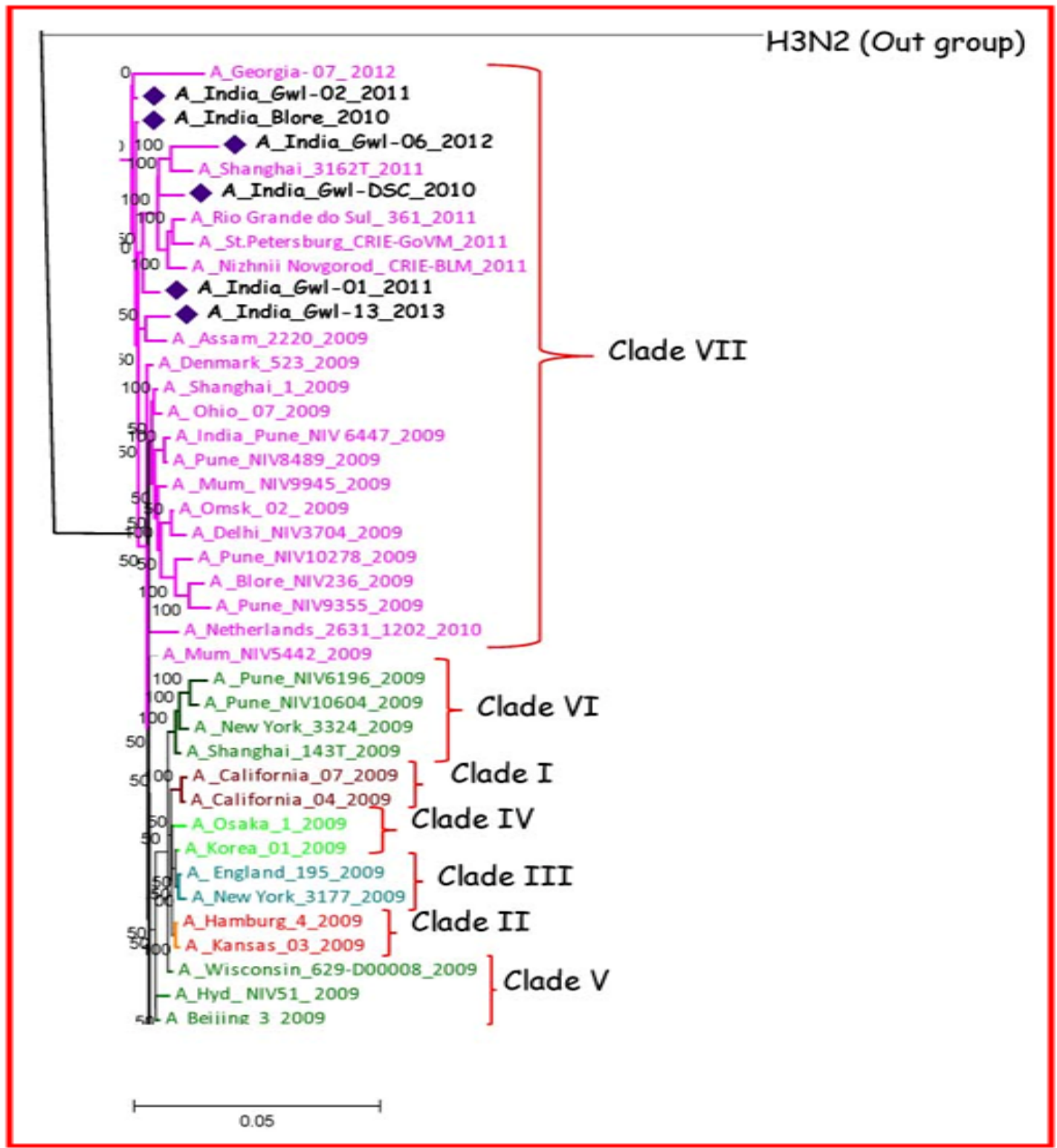

Fugure 3: Complete HA gene based Bayesian phylogeny H1N1pdm virus 2009-2013.

Oseltamivir resistance assay. (A) RT-PCR amplification and RFLP. (B) SYBR green real time RT-PCR amplification plot and dissociation curve. (C) Sequence confirmation of $\mathrm{H} 275 \mathrm{Y}$ mutation. 
Transmission of pandemic Influenza virus in 209 countries and overseas territories, with 14711 deaths since the first reports of the virus in human in April 2009 diversified into seven distinct clades. However virus activity levels were found comparatively low in Asia. Indian scenario revealed stable Influenza activity but elevated in western India, continued to decline substantially in northern India, and remained low overall in southern and eastern India [15]. Most genetic changes in H1N1pdm to date have not been clearly linked to changes in antigenicity, disease severity, antiviral drug resistance, or transmission efficiency. However, rapid evolution rate characteristic of influenza viruses suggest that changes in antigenicity are inevitable in future [17]. With the number of reported pandemic cases of H1N1 virus in many parts of the world and continued viral persistence with elevated activity in India and nearby countries (Nepal, Sri Lanka, Bangladesh), has given an urgent need to track the global dispersion of this virus in humans.

Present study, demonstrates the virus isolates during post pandemic phase belonged to clade VII. All Indian viruses sequenced till date belonged to clade VII with signature change 'S220T'. However a shift of clade VII was observed in Indian isolates over clade V and clade VI which appeared first in Asia during pandemic period (MaySeptember 2009). Soon after that, molecular epidemiology studies revealed cosmopolitan clade VII has established and positively selected in the country which was evidenced by identification of all circulating Indian isolates belonging to clade VII from 2009-2012. The continued circulation of this virus in India from 2009-till date is a serious concern and required in depth investigation and to keep continuous surveillance at virus genomic level which led to emergence of new subtypes or increased pathogenicity. Therefore, in depth molecular investigation of circulating H1N1pdm virus, suspected clinical samples from Gwalior, India during 2012-2013 were investigated. The clinical picture of the patients revealed the same pattern as was reported in 2009-2011 [18,19] but there was moderate number of H1N1pdm cases in 2012-2013. In this study, one Indian isolate with travel history confirmed by virus specific CPE, HA as well as CDC Real time RT-PCR was selected for complete HA gene characterization. The nucleotide sequence analysis revealed that there is no significant difference among viruses recovered from India from previous years. Diversity of the 2012 Indian isolate at the amino acid level with respect to the prototype strain was found to be $98.9 \%$ in the HA gene. Substitution S220T (HA) specific to clade VII isolates was adequate to lineate the isolates in HA-based phylogeny. Most of the amino acid changes were conservative, involving interchanges of amino acids having same physicochemical properties. However, few major non-conservative changes between Indian isolate were also observed. Compared to the prototype strain, glutamic acid was replaced by a strongly basic amino acid lysine at position 391 (HA); cyclic proline to acyclic serine at position 100 (HA) were also recorded in Indian $2012 \mathrm{H} 1 \mathrm{~N} 1 \mathrm{pdm}$ virus sequenced in this study. However, the significance of these substitutions need to be further addressed in details.

To identify genetic lineage of H1N1pdm virus, phylogenetic analysis was conducted for complete HA gene sequences retrieved from GenBank from 2009-2012 including all the available H1N1pdm viruses from India sequenced till date. Full HA based phylogenetic analysis revealed existing seven discrete clades of H1N1pdm virus circulating globally. Phylogenetic tree based on genome information comprised of all representative $\mathrm{H} 1 \mathrm{~N} 1 \mathrm{pdm}$ clades from diverse geographical origin which included maximum number of representative H1N1pdm from all the affected areas. Maximum numbers of isolates were grouped into clade VII. The clade I included prototype California/04 and California/07 virus isolated first during H1N1pdm [19]. All Indian isolates (2009-2011) were grouped in clade VII except Hyd/NIV51/2009 and Pune/NIV6196/2009 virus isolated during initial pandemic phase grouped into clade V and VI respectively [20]. Clade VII is identified as predominant circulating clade in India, Asia as well as globally [19]. Phylogenetic analysis of all Indian H1N1pdm complete genome sequenced so far demonstrated that earliest isolate from Hyderabad (A/ India/Hyd/NIV51/2009) during initial pandemic phase was a clade $\mathrm{V}$ isolate. Two other isolates from Pune during later pandemic phase (A/ India/pune/NIV6196/2009, A/India/pune/NIV10604/2009) belonged to clade VI. Both the cases were not directly associated with any foreign travel history that is why it is not clear whether the clade evolved within the country or were imported into the country. All other Indian isolates from last pandemic phase to post pandemic phase belonged to clade VII. Two initial Indian isolates belonging to clade VII had a foreign travel history and thus may be indicative of the fact that clade VII was introduced from an external source [21]. Selection pressure analysis in previously isolated Indian isolates revealed clade VII signature mutations is responsible for circulation of this cosmopolitan clade in India $[13,19]$.Therefore it may be possible that clade VII is favourably selected as dominant H1N1pdm lineage in India.

The epidemiological data demonstrated that early cases in India were imported through foreign travellers; however soon after, the indigenous evolution and transmission resulted in wide spread of the virus. As more epidemiological and sequence data is becoming available, a clear picture of virus evolution in last four years has been achieved.

This study is carried out to characterize the true genetic nature of recently circulating Indian $\mathrm{H} 1 \mathrm{~N} 1 \mathrm{pdm}$ virus. This study clearly indicates that the cosmopolitan clade VII viruses are continuously circulating in India. This molecular epidemiology information will facilitate better pandemic planning and response capacity for future epidemiological surveillance in Indian subcontinent and abroad [22-29].

\section{Acknowledgments}

The authors are thankful to Prof. M.P. Kaushik Director Defence Research and Development Establishment, Ministry of Defence, Government of India, for his support, constant inspiration and providing the necessary facilities for this study. The authors are also thankful to our clinical collaborators (Chief Medical Health Officer, Gwalior) for providing H1N1pdm suspected clinical samples.

\section{Ethical Approval}

This work has been approved by the Defence Research and Development Establishment, Gwalior "Institutional Bio Safety and Ethical Committee" which has further been approved by Department of Biotechnology, Ministry of Science \& Technology, Govt. of India. A formal, written consent was obtained for each subject.

\section{Funding}

This work was carried out in Defence Research and Development Establishment, Gwalior, India an institute under the ministry of defence, Government of India.

\section{References}

1. Neumann G, Noda T, Kawaoka Y (2009) Emergence and pandemic potential of swine-origin H1N1 influenza virus. Nature 2009 459: 931-939.

2. Rambaut A, Pybus OG, Nelson MI, Viboud C, Taubenberger JK, et al. (2008) The genomic and epidemiological dynamics of human influenza $A$ virus. Nature 453: 615-619.

3. Reid EH, Fanning TG, Hultin JV, Taubenberger JK (1999) Origin and evolution of the 1918 Spanish Influenza virus hemagglutinin gene. Proc Natl Acad Sc USA 96: 1651-1656.

4. CDC protocol of real-time RTPCR for swine influenza A (H1N1) (2009)

5. Chen GW, Shih SR (2009) Genomic signatures of influenza A pandemic (H1N1) 2009 virus. Emerg Infect Dis 15: 1897-1903. 
Citation: Shashi S, Gaurav J, Paban Dash K, Parida MM (2015) Laboratory Investigation and Molecular Epidemiology of H1N1pdm Virus 2012-2013 from India. J Phylogen Evolution Biol 3: 139. doi:10.4172/2329-9002.1000139

Page 7 of 7

6. Jagannatha RSR, Rao MJ, Swamy N, Umapathy BL (2011) Profile of H1N1 infection in a tertiary care center. Indian J Pathol Microbiol 54: 323-325.

7. Rana H, Parikh P, Shah AN, Gandhi S (2012) Epidemiology and clinical outcome of H1N1 in Gujarat from July 2009 to March 2010. J Assoc Physicians India 60: 95-97.

8. Broor S, Krishnan A, Roy DS, Dhakad S, Kaushik S, et al. (2012) Dynamic patterns of circulating seasonal and pandemic A (H1N1) pdm09 Influenza viruses from 2007-2010 in and around Delhi, India. PLoS ONE 7:

9. Choudhary A, Singh S, Khare S, Rai A, Rawat DS, et al. (2012) Emergence of pandemic 2009 influenza A H1N1, India. Indian J Med Res 135: 534-537.

10. Deem MW, Pan K. (2009) The epitope regions of H1-subtype influenza A, with application to vaccine efficacy. Protein Eng Des Sel 22: 543-546.

11. Sharma S, Joshi G, Dash PK, Thomas M, Athmaram TN, et al. (2013) Molecular Epidemiology and Complete Genome Characterization of H1N1pdm Virus from India. PLoS ONE 8:

12. Chakrabarti AK, Pawar SD, Cherian SS, KORATKAR SS, Jadhav SM, et al. (2009) Characterization of the Influenza A H5N1 viruses of the 2008-09 outbreaks in India reveals a third introduction and possible endemecity. PLoS ONE 4:

13. Hoskins JM (1976) Identification of virus isolates, In virological procedures. Morrison and Gibb Lmt. Butter worths, London, pp.184-186.

14. Edgar RC (2004) MUSCLE: multiple sequence alignment with high accuracy and high throughput. Nucleic Acids Res 32: 1792-1797.

15. Ronquist F, Huelsenbeck JP (2003) MrBayes 3: Bayesian phylogenetic inference under mixed models. Bioinformatics 19: 1572-1574.

16. Ortiz JR, Sotomayor V, Uez OC, Oliva O, Bettels D, et al. (2009) Strategy to enhance influenza surveillance worldwide. Emerg Infect Dis 15: 1271-1278.

17. Garten RJ, Davis CT, Russell CA, Shu B, Lindstorm S, et al. (2009) Antigenic and genetic characteristics of swine-origin $2009 \mathrm{~A}(\mathrm{H} 1 \mathrm{~N} 1)$ influenza viruses circulating in humans. Science 325:197-201.

18. Dawood FS, Jain S, Finelli L, Shaw MW, Lindstrom S, et al. (2009) Emergence of a novel swine-origin influenza A (H1N1) virus in humans. N Engl J Med 360: 2605-2615.

19. Schrauwen EJ, Herfst S, Chutinimitkul S, Bestebroer TM, Rimmelzwaan GF, et al. (2011) Possible Increased Pathogenicity of Pandemic (H1N1) 2009 Influenza Virus upon Reassortment. Emerg Infect Dis 17: 200-208.

20. Brookes SM, Nunez A, Choudhury B, Matrosovich M, Essen SC, et al. (2011) Replication, pathogenesis and transmission of pandemic (H1N1) 2009 virus in nonimmune pigs. PLoS ONE

21. Pan C, Cheung B, Tan S, Li C, Li L, et al. (2010) Genomic signature and mutation trend analysis of pandemic (H1N1) 2009 influenza A virus. PLoS ONE

22. World Health Organization (WHO) (2009) Human infection with pandemic (H1N1)2009 virus: updated interim WHO guidance on global surveillance.

23. Vijaykrishna D, Poon LLM, Zhu HC, Ma SK, Li OTW, et al. (2010) Reassortment of pandemic H1N1/2009 influenza A virus in swine. Science 328: 1529.

24. York I, Donis RO (2013) The 2009 Pandemic Influenza Virus: Where Did It Come from, Where Is It Now, and where is it going? Curr Top Microbio Immunol. 370: 241-257

25. Sharma S, Parida M, Shukla J, Rao PV (2011) Molecular epidemiology of nove swine origin Influenza virus (S-OIV) from Gwalior, India 2009. Virol J 8: 280.

26. Nelson M, Spiro D, Wentworth D, Beck E, Fan J, et al. (2009) The early diversification of Influenza A/H1N1pdm. PLoS Curr 1: RRN1126.

27. Li W, Shi W, Qiao H, Ho SYW, Luo A, et al. (2011) Positive selection on haemagglutinin and neuraminidase genes on $\mathrm{H} 1 \mathrm{~N} 1$ influenza viruses. Virology J 8: 183.

28. Potdar VA, Chadha MS, Jadhav SM, Mullick J, Cherian SS, et al. (2010) Genetic characterization of the Influenza A pandemic (H1N1)2009 virus isolates from India. PLoS ONE 5: e9693.

29. Nukiwa N, Suzuki A, Furuse Y, Shimabukuro K, et al. (2010) Simplified screening method for detecting oseltamivir resistant pandemic influenza $A$ (H1N1) 2009 virus by a RT-PCR/restriction fragment length polymorphism assay. J Virol Methods 170: 165-168. 